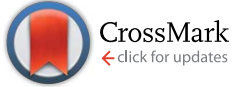

Cite this: RSC Adv., 2017, 7, 7990

\title{
The formation mechanisms of porous silicon prepared from dense silicon monoxide $\uparrow$
}

\author{
Shao-zhong Zeng, ${ }^{\text {ab }}$ Xierong Zeng, ${ }^{\text {abc }}$ Lin Huang, ${ }^{a}$ Hongliang Wu, ${ }^{a}$ Yuechao Yao, ${ }^{a}$ \\ Xianfeng Zheng ${ }^{d}$ and Jizhao Zou*a
}

Porous silicon (PSi) has been widely investigated for use in many applications. PSi is usually prepared through the selective etching of silicon. Recently, PSi has been prepared by reducing dense silicon monoxide $(\mathrm{SiO})$ with magnesium. Although the porosity has been confirmed to be a result of the selective acid dissolution of $\mathrm{MgO}$, the formation mechanisms of the composite of $\mathrm{MgO}$ and PSi are not very clear. To better understand the formation mechanisms, we synthesized two types of PSi by reducing compact $\mathrm{SiO}$ and disproportionate $\mathrm{SiO}(\mathrm{d}-\mathrm{SiO}$ ) with different magnesium content. The BET surface area and pore volume of these PSi samples first increased and then decreased. The highest BET surface area was 304 and $328 \mathrm{~m}^{2} \mathrm{~g}^{-1}$ for PSi prepared from SiO and d-SiO, respectively. These BET surface areas are among the highest for PSi prepared from dense SiO or silica. An inductive effect of the preformed silicon network in $\mathrm{d}-\mathrm{SiO}$ was found by contrasting the pore characteristics of the two types of PSi derived from $\mathrm{SiO}$ and $\mathrm{d}-\mathrm{SiO}$. Accordingly, we suggested two models for the formation mechanisms of PSi from $\mathrm{SiO}$ and d-SiO.

Received 8th December 2016 Accepted 17th January 2017

DOI: 10.1039/c6ra27929e

www.rsc.org/advances the reaction of dense silica and $\mathrm{Mg}$. However, several pioneering works have shown that PSi with high porosity formed unexpectedly in the magnesiothermic reduction of nonporous silica and silicon monoxide ( $\mathrm{SiO})^{\mathbf{1 , 2 2 , 2 3}}$ Although the porosity of PSi has been confirmed to be a result of the selective acid dissolution of $\mathrm{MgO},{ }^{1}$ the formation mechanisms of the composite of $\mathrm{MgO}$ and PSi is not very clear.

Compared with silica, SiO has a high silicon content and low heat release per mole silicon in the magnesiothermic reduction, ${ }^{24}$ which facilitates the scalable production of $\mathrm{PSi}^{{ }^{17}}$ Therefore, we focused on the reduction reaction between SiO and $\mathrm{Mg}$. SiO has a homogeneous amorphous structure which is a metastable phase and converts into a composite of silicon and $\mathrm{SiO}_{2}$ at high temperature. ${ }^{25}$ The silicon and $\mathrm{SiO}_{2}$ in this composite form two networks interpenetrated with each other, ${ }^{25}$ which is different from the original homogeneous SiO material. These differences may lead to different reactivity with $\mathrm{Mg}$ and different pore structure of the final product. A detailed study of the differences in the reaction of $\mathrm{SiO}$ and disproportionate $\mathrm{SiO}$ (d-SiO) with $\mathrm{Mg}$ will further our understanding of the formation mechanisms of PSi. In this work, two types of PSi were prepared through the magnesiothermic reduction of $\mathrm{SiO}$ and d-SiO with different $\mathrm{Mg}$ content. We observed an inductive effect of the preformed silicon network in d-SiO by contrasting the pore characteristics of the two types of PSi derived from SiO and d-SiO. The formation mechanisms of the composite of $\mathrm{MgO}$ and PSi were thoroughly studied by analysing the relationship between the pore structures and $\mathrm{Mg}$ content in magnesiothermic reduction. 


\section{Experimental}

\section{Sample preparation}

$\mathrm{SiO}$ (200 mesh, 99.99\%) and $\mathrm{Mg}$ (100 mesh, 99.8\%) were purchased from Macklin Co. (Shanghai, China). First, $4.40 \mathrm{~g}$ of $\mathrm{SiO}$ was mixed thoroughly with different magnesium contents $(0.60,1.20,1.80$ and $2.40 \mathrm{~g})$ using a ball grinder. The mixture was transferred into a tubular furnace, heated to $300{ }^{\circ} \mathrm{C}$ at a heating rate of $5{ }^{\circ} \mathrm{C} \min ^{-1}$, held at $300{ }^{\circ} \mathrm{C}$ for $3 \mathrm{~h}$, heated to $500{ }^{\circ} \mathrm{C}$ at a heating rate of $2{ }^{\circ} \mathrm{C} \min ^{-1}$ and held at $500{ }^{\circ} \mathrm{C}$ for $12 \mathrm{~h}$. All the heat treatments were done under Ar flow $(50 \mathrm{~mL}$ $\min ^{-1}$ ). After cooling, the mixture was added slowly to an excess amount of $10 \mathrm{wt} \% \mathrm{HCl}$, stirred for $12 \mathrm{~h}$, vacuum-filtered, washed with large amounts of water and ethanol and dried at $80^{\circ} \mathrm{C}$. The PSi with $0.60,1.20,1.80$ and $2.40 \mathrm{~g}$ was denoted as PSi-06, PSi-12, PSi-18 and PSi-24, respectively. d-SiO was obtained by heat treating $\mathrm{SiO}$ at $950{ }^{\circ} \mathrm{C}$ under Ar flow $(50 \mathrm{~mL}$ $\min ^{-1}$ ) for $4 \mathrm{~h}$. PSi was similarly synthesized from d-SiO and named as PSi-06D, PSi-12D, PSi-18D and PSi-24D, respectively.

\section{Characterizations}

Powder X-ray diffraction (XRD) patterns were recorded on a Bruker $\mathrm{D} 8$ Advance diffractometer using $\mathrm{Cu}-\mathrm{K} \alpha$ radiation (40 $\mathrm{kV}$ and $200 \mathrm{~mA}$ ). Data were collected from $2 \theta=15^{\circ}$ to $80^{\circ}$ with a step of $0.02^{\circ}$ and a scanning rate of $0.2^{\circ} \mathrm{s}^{-1}$. Nitrogen isotherms were measured at $77 \mathrm{~K}$ using an ASAP 2020 system (Micromeritics Co.). The samples were pretreated at $373 \mathrm{~K}$ and a pressure of less than $1.33 \mathrm{~Pa}$ for $1 \mathrm{~h}$ with further degassing at $473 \mathrm{~K}$ and a pressure of less than $26.7 \mathrm{~Pa}$ for $4 \mathrm{~h}$. The specific surface area was calculated using the Brunauer-Emmett-Teller (BET) method based on the adsorption data obtained within a partial pressure $\left(P / P_{\mathrm{o}}\right)$ range of $0.05-0.20$, and the total pore volume was determined from the amount of nitrogen adsorbed at $P / P_{\mathrm{o}}=0.99$. The pore size distribution was calculated by the original density functional theory (DFT) included in the software ASAP 2020 system. The average pore diameter was calculated from Barrett-Joyner-Halenda (BJH) analyses. Scanning electron microscopy (SEM) and energy dispersive spectroscopy (EDS) were carried out on a field emissionSU-70 microscope. TEM images were obtained using a JEOL JEM2010 electron microscope.

\section{Results and discussion}

The powder XRD patterns of the composites of PSi and MgO are shown in Fig. 1. As the magnesium content increased, the diffraction peaks of silicon and $\mathrm{MgO}$ (Fig. 1a and c) strengthened, and the peak of amorphous SiO weakened, which demonstrates that an increasing amount of $\mathrm{SiO}$ was converted into PSi and $\mathrm{MgO}$. After the removal of $\mathrm{MgO}$, only the peaks corresponding to silicon and amorphous SiO remained (Fig. 1b and d). According to the Scherrer formula, the crystallite sizes of $\mathrm{MgO}$ and silicon were obtained from the half width of the strongest peaks. As shown in Table $\mathrm{S} 1, \uparrow$ the crystallite size of $\mathrm{MgO}$ and silicon were approximately $10 \mathrm{~nm}$. After the removal of $\mathrm{MgO}$, the crystallite size of silicon increased in the PSi obtained
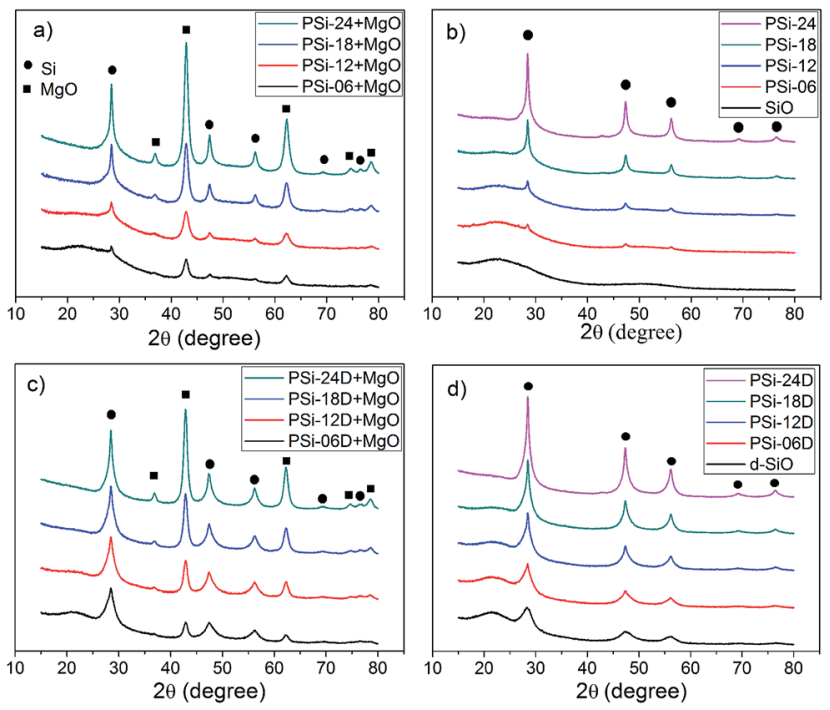

Fig. 1 Powder XRD patterns of the products obtained from SiO before (a) and after (b) removing MgO. Powder XRD patterns of the products obtained from d-SiO before (c) and after (d) removing $\mathrm{MgO}$.

from $\mathrm{SiO}$, whereas that of the silicon obtained from d-SiO remained unchanged. However, the larger crystallite size is probably an illusion rather than real growth because the weak peaks of the PSi from $\mathrm{SiO}$ and the broad peak of amorphous $\mathrm{SiO}$ limit the accuracy of the estimation of crystallite size. The crystallite size of silicon in PSi-06D (6 nm) was obviously larger than that of d-SiO $(4 \mathrm{~nm})$, which suggests that the silicon reduced by $\mathrm{Mg}$ grows on the preformed silicon network. To gain further insight into the reaction process, four samples containing $0.60 \mathrm{~g}$ of $\mathrm{Mg}+4.40 \mathrm{~g}$ of $\mathrm{SiO}, 0.60 \mathrm{~g}$ of $\mathrm{Mg}+4.40 \mathrm{~g}$ of d$\mathrm{SiO}, 2.40 \mathrm{~g}$ of $\mathrm{Mg}+4.40 \mathrm{~g}$ of $\mathrm{SiO}$ and $2.40 \mathrm{~g}$ of $\mathrm{Mg}+4.40 \mathrm{~g}$ of d$\mathrm{SiO}$ were heat-treated at $300{ }^{\circ} \mathrm{C}$ for $3 \mathrm{~h}$. The powder XRD patterns of the corresponding products are shown in Fig. S1. $\dagger$ All the patterns contain strong $\mathrm{Mg}$ peaks, proving that part of the $\mathrm{Mg}$ remains under these reaction conditions. The peaks at $2 \theta=24.24$ and 40.12 belong to Zintl-phase $\mathrm{Mg}_{2} \mathrm{Si}$ and demonstrate the formation of $\mathrm{Mg}_{2} \mathrm{Si}$ under these conditions. A wide peak at $42.8^{\circ}$ is attributed to the strongest main peak of $\mathrm{MgO}$ (200), which suggests that the MgO grains were very small in these samples. Obviously, $\mathrm{MgO}$ is the most stable and thermodynamically favourable form of $\mathrm{Mg}$. However, not all the $\mathrm{Mg}$ forms $\mathrm{MgO}$ at low temperature because of the high activation energy of the corresponding reaction. Instead, part of the $\mathrm{Mg}$ forms $\mathrm{Mg}_{2} \mathrm{Si}$ owing to the fast generation rate of this compound. ${ }^{26}$ Therefore, the formation of $\mathrm{Mg}_{2} \mathrm{Si}$ is the result of a dynamic effect rather than a thermodynamic effect.

As shown in Fig. 2, the surface morphology of the PSi from SiO changed from randomly distributed particles to a spongelike network when the $\mathrm{Mg}$ content changed from 0.6-1.8 g. The surface morphology of the PSi prepared with $2.4 \mathrm{~g}$ of $\mathrm{Mg}$ transformed into a flat surface with visible pores, and many particles with diameters of 20-100 nm grew on the surface of large particles. The netlike surface morphology of PSi-06D was different from that of PSi-06, which probably resulted from the 


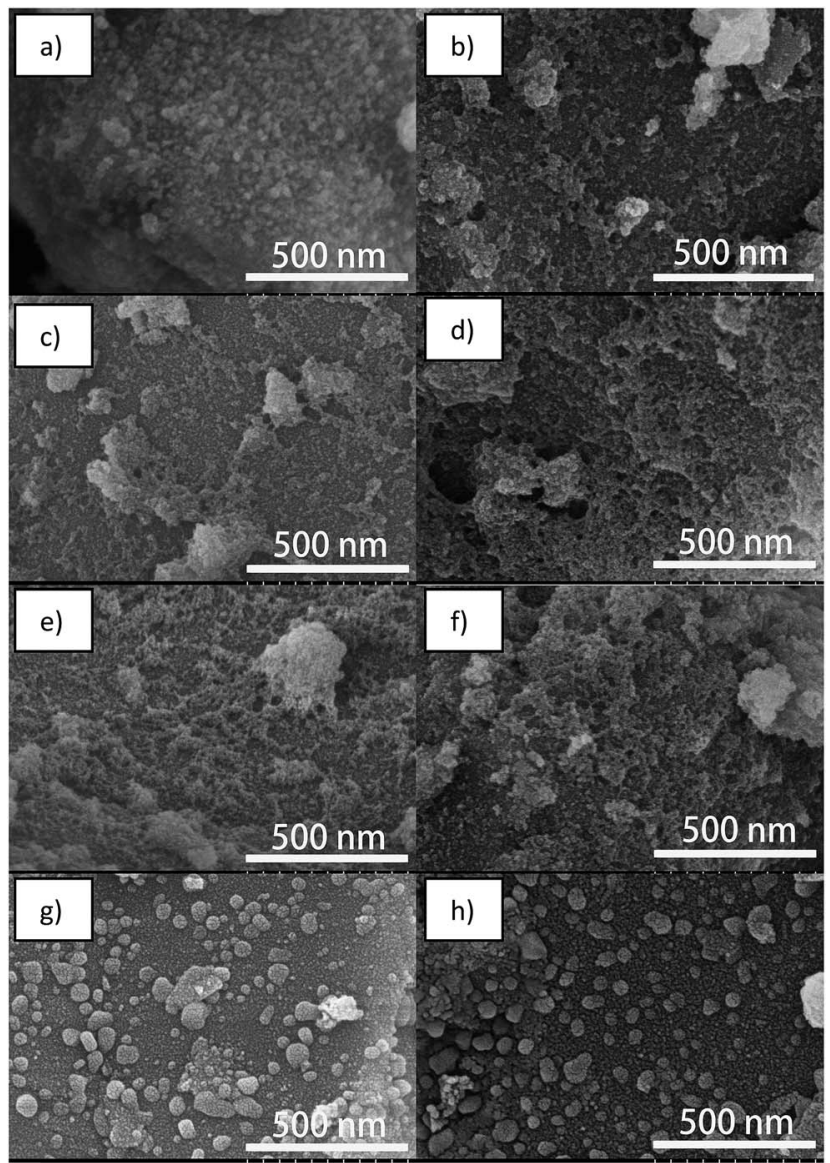

Fig. 2 SEM images of PSi prepared by reducing $4.40 \mathrm{~g}$ of SiO (left) and $\mathrm{d}-\mathrm{SiO}$ (right) with different $\mathrm{Mg}$ contents; from top to bottom, the $\mathrm{Mg}$ content was $0.6,1.2,1.8$ and $2.4 \mathrm{~g}$

induction effect of the preformed silicon network in the d-SiO. The preformed silicon network plays two roles. First, it acts as a nucleus for the growth of the newly formed silicon; second, it acts as a magnesium transfer channel because the diffusion of magnesium is faster in silicon than in MgO. ${ }^{26}$ As a result of the inductive effect, the surface morphologies of PSi-12D and PSi18D were almost the same as that of PSi-06D, except for the difference in porosity, which suggests that the d-SiO particles were transferred into PSi from the outside to the inside along with the increase of the $\mathrm{Mg}$ content. PSi-24D was significantly different from the PSi prepared with low $\mathrm{Mg}$ content and appeared similar to PSi-24, but with larger pores.

The TEM images of PSi-06 (Fig. 3a) and PSi-06D (Fig. 3b) show dense cores coated with PSi, which is an expected result because the lack of $\mathrm{Mg}$ can only convert the outside of the particles into PSi. Dense cores should also be present in PSi-12 and PSi-12D but are difficult to clearly observe using TEM (Fig. 3c and d) because of the thicker PSi coating. The TEM images of PSi-18 (Fig. 3e) and PSi-18D (Fig. 3f) show a highly developed pore network without dense cores. The TEM images of PSi-06D, PSi-12D and PSi-18D demonstrate that the thickness of the PSi coating increased with the $\mathrm{Mg}$ content and the pore structure of the PSi coating was not obviously different among

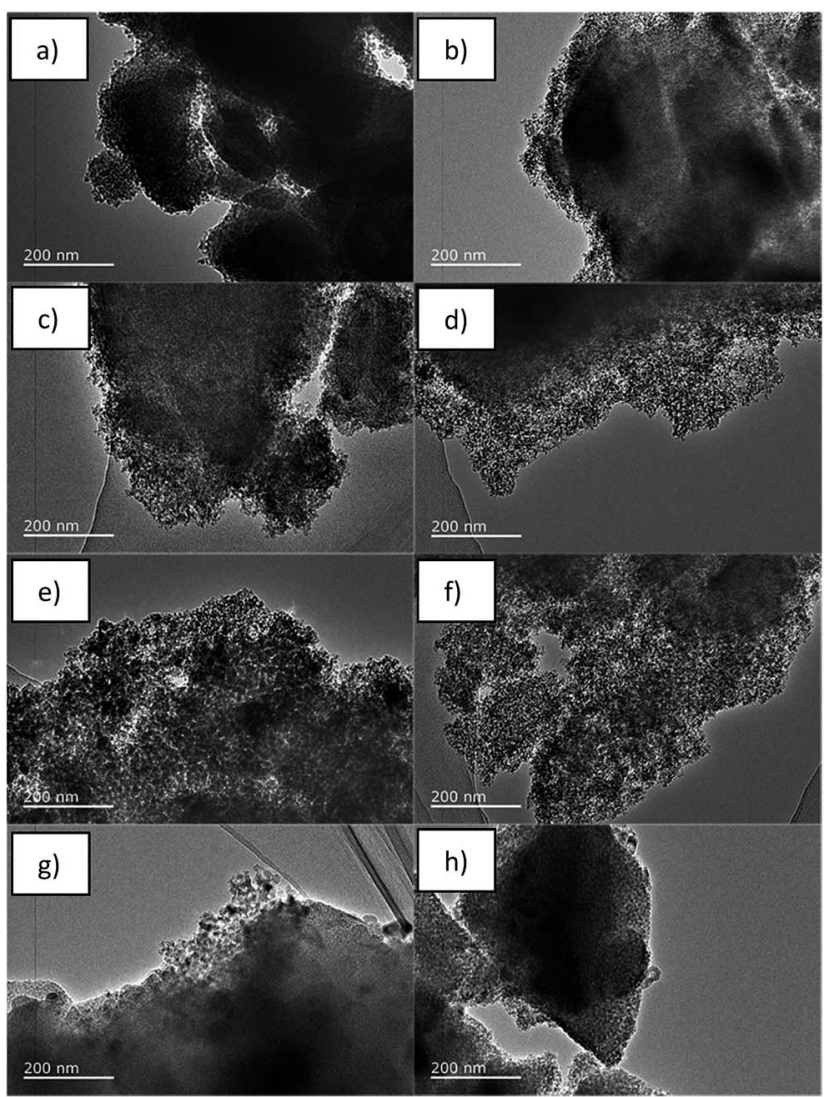

Fig. 3 TEM images of PSi prepared by reducing $4.40 \mathrm{~g}$ of $\mathrm{SiO}$ (left) and $\mathrm{d}$-SiO (right) with different $\mathrm{Mg}$ contents; from top to bottom, the $\mathrm{Mg}$ content was $0.6,1.2,1.8$ and $2.4 \mathrm{~g}$

these samples. The pore diameter in PSi-24 (Fig. 3g) was decreased compared with that of PSi-18. The pore networks in PSi-24 and PSi-24D contained some degree of order compared with the totally disordered network in the other PSi samples. High-resolution TEM images (Fig. S2 and S3†) show that all the PSi samples contained silicon grains with sizes of $\sim 10 \mathrm{~nm}$, which is consistent with the XRD results. The insets of Fig. S2 and $\mathrm{S} 3 \uparrow$ showed the selected area electron diffraction (SAED) patterns of PSi-24 and PSi-24D, which were the characteristic reflections of polycrystalline silicon. The three diffraction rings corresponded to $\mathrm{Si}$ (111), (220) and (311) crystal planes of cubic phase. The SAED pattern of PSi-24D also showed rings of high index crystal planes because of its developed crystal structure as compared with PSi-24.

The composition and element distribution of PSi were obtained from EDS analyses. As shown in Table S2, $\dagger$ the silicon content increased and oxygen content decreased along with the increase of $\mathrm{Mg}$ content, which matched with the powder XRD results (Fig. 1) and TEM images (Fig. 3). The highest silicon contents of PSi samples prepared from SiO and d-SiO were 85.05 (PSi-24) and 90.25 wt\% (PSi-24D), respectively. The Mg contents for all these PSi samples were $\sim 1 \mathrm{wt} \%$, demonstrating an effective removal of $\mathrm{MgO}$ by $\mathrm{HCl}$. The element distributions of PSi-18 and PSi-24 were shown in Fig. S4 and S5, $\uparrow$ respectively. The elements silicon, oxygen and $\mathrm{Mg}$ were uniformly 
distributed in these samples. The element distribution of other samples was similar and did not show.

Nitrogen adsorption-desorption isotherms were measured at $77 \mathrm{~K}$ to calculate the surface area and thoroughly analyse the pore characteristics of the PSi. According to the classification of the International Union of Pure and Applied Chemistry, all the nitrogen adsorption-desorption isotherms (Fig. $4 \mathrm{a}$ and b) were type IV with H3-type hysteresis loops. The isotherm of PSi-06 was close to type II because the pores of PSi-06 were almost uniformly distributed in the range of $2-50 \mathrm{~nm}$. The multilayer adsorption of these large pores gives rise to a type II/IV isotherm.

The BET surface area and pore volume (Table 1) of these PSi samples first increased and then decreased. These parameters increased in turn when the magnesium content increased from 0.60 to $1.80 \mathrm{~g}$ and decreased when the magnesium content increased from 1.80 to $2.40 \mathrm{~g}$. The highest BET surface area was 304 and $328 \mathrm{~m}^{2} \mathrm{~g}^{-1}$ for PSi obtained from $\mathrm{SiO}$ and $\mathrm{d}-\mathrm{SiO}$, respectively, which are $50 \%$ larger than the surface area of the PSi prepared from dense SiO with sufficient $\mathrm{Mg}\left(212 \mathrm{~m}^{2} \mathrm{~g}^{-1}\right)$. To the best of our knowledge, these values are among the highest of those obtained for PSi prepared by reducing dense silica or $\mathrm{SiO}$ with $\mathrm{Mg}^{1,17,22,23}$ Unexpectedly, the highest $\mathrm{Mg}$ content did
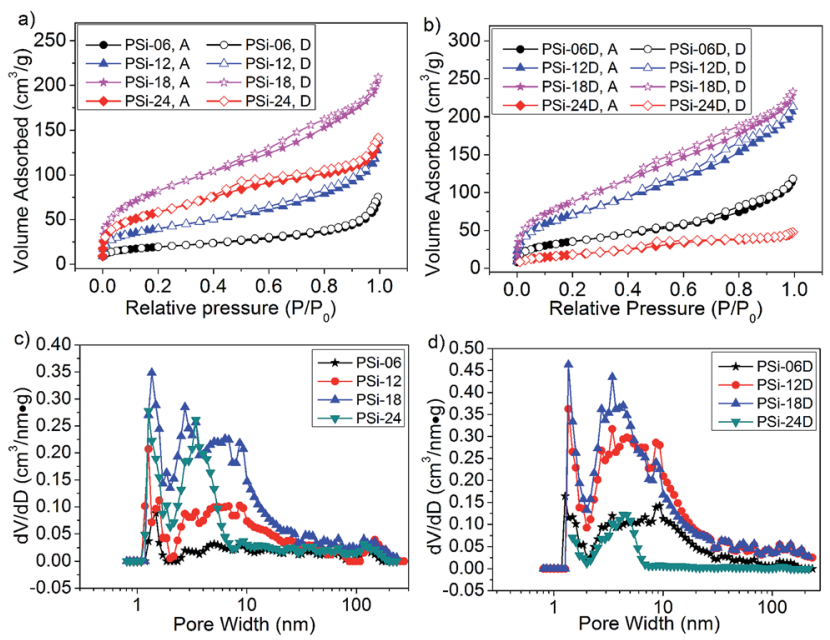

Fig. 4 Nitrogen adsorption (filled) and desorption (unfilled) curves of the PSi obtained from (a) SiO and (b) d-SiO; DFT pore size distribution of PSi obtained from (c) $\mathrm{SiO}$ and (d) d-SiO.

Table 1 BET surface area, pore volume and average pore diameter of the PSi

\begin{tabular}{llll}
\hline Sample number & $\begin{array}{l}\text { BET surface } \\
\text { area }\left(\mathrm{m}^{2} \mathrm{~g}^{-1}\right)\end{array}$ & $\begin{array}{l}\text { Pore volume } \\
\left(\mathrm{cm}^{3} \mathrm{~g}^{-1}\right)\end{array}$ & $\begin{array}{l}\text { Average pore } \\
\text { diameter }(\mathrm{nm})\end{array}$ \\
\hline PSi-06 & 69 & 0.11 & 8.7 \\
PSi-12 & 145 & 0.20 & 7.0 \\
PSi-18 & 304 & 0.31 & 4.9 \\
PSi-24 & 212 & 0.21 & 4.6 \\
PSi-06D & 130 & 0.18 & 6.1 \\
PSi-12D & 267 & 0.32 & 5.1 \\
PSi-18D & 328 & 0.35 & 4.5 \\
PSi-24D & 67 & 0.07 & 4.1
\end{tabular}

not correspond to the largest surface area and pore volume, which could be due to the larger pores formed at high $\mathrm{Mg}$ content through the confusion of $\mathrm{MgO}$ grains. Due to the developed silicon grains of PSi-24D (Table S1 and inset of Fig. S3 $\dagger$ ), the BET surface area and pore volume of PSi-24D were far smaller than those of PSi-18D and PSi-24.

Remarkably, the surface area and pore volume of PSi-06D and PSi-12D were approximately two times larger than those of PSi-06 and PSi-12, which probably resulted from the inductive effect of the preformed silicon network in the d-SiO. The pore size distributions of PSi (Fig. $4 \mathrm{c}$ and d) were calculated using DFT. All PSi contained some micropores less than $2 \mathrm{~nm}$ in size. The pore size distributions of the PSi from SiO (Fig. 4c) changed greatly along with the increase of $\mathrm{Mg}$ content. The pore size of PSi-06 was widely distributed in the range of 2-50 nm, whereas those of PSi-12 and PSi-18 were mainly distributed in the range of 2-20 nm; moreover, the shapes of the two curves had a certain degree of similarity. The pore size of PSi-24 mainly centred in the range of $2-8 \mathrm{~nm}$ with a peak at $3.4 \mathrm{~nm}$. The pore sizes of PSi-06D, PSi-12D and PSi-18D (Fig. 4d) were distributed in the range of $2-20 \mathrm{~nm}$, and the shapes of these curves showed high similarities. For the PSi from d-SiO, the pores with sizes of 2-20 $\mathrm{nm}$ increased proportionally when the $\mathrm{Mg}$ content increased from 0.60 to $1.80 \mathrm{~g}$. This result suggests that the d-SiO particles transferred into PSi from outside to inside with the increase of $\mathrm{Mg}$ content, which agrees with the TEM results. The similarity in the pore size distribution of PSi-06D, PSi-12D and PSi-18D is consistent with the similarity of the SEM images, which is evidence for the inductive effect of the preformed silicon network in d-SiO. By contrast, the similarity in the pore size distribution of PSi-06, PSi-12 and PSi-18 is not obvious because there is no preformed silicon network in untreated SiO.

Accordingly, we suggested two models for the formation mechanisms of the PSi derived from $\mathrm{SiO}$ and d-SiO, respectively. The amorphous $\mathrm{SiO}$ (Fig. 5a) reacted with $\mathrm{Mg}$ to form randomly distributed silicon and $\mathrm{MgO}$ nuclei at the surface of the SiO particles. Because $\mathrm{Mg}$ was present in local excess at the surface of $\mathrm{SiO}$, the silicon nuclei instantly converted into $\mathrm{Mg}_{2} \mathrm{Si}$ nuclei. Both $\mathrm{Mg}_{2} \mathrm{Si}$ (Fig. 5b) and $\mathrm{MgO}$ grew into the inside of the SiO particle, which was supported by Fig. S1. $\dagger$ When the temperature increased, $\mathrm{Mg}_{2} \mathrm{Si}$ further reacted with adjacent $\mathrm{SiO}$ to form silicon and $\mathrm{MgO}$. The silicon and $\mathrm{MgO}$ formed two networks that interpenetrated with each other. After removing the $\mathrm{MgO}$ network by acid, the silicon network remained as the PSi samples. At $\mathrm{Mg}$ content lower than $1.8 \mathrm{~g}$ per $4.4 \mathrm{~g}$ of SiO, the core of the SiO particle did not convert into PSi and $\mathrm{MgO}$ (Fig. 5c), which was confirmed by Fig. 3. Moreover, the BET surface area and pore volume of PSi (Table 1) were near-linear with $\mathrm{Mg}$ content when $\mathrm{Mg}$ was lower than $1.8 \mathrm{~g}$ per $4.4 \mathrm{~g}$ of $\mathrm{SiO}$ and deviated from linear relationship at higher $\mathrm{Mg}$ content, which was an indirect evidence for turning point happened at $1.8 \mathrm{~g}$ of $\mathrm{Mg}$ and transformation from outside to inside. At $\mathrm{Mg}$ content higher than $1.8 \mathrm{~g}$ per $4.4 \mathrm{~g}$ of SiO, the whole SiO particle converted into PSi and $\mathrm{MgO}$ (Fig. 5d), which was confirmed by TEM images (Fig. 3e-h).

The reaction between $\mathrm{d}-\mathrm{SiO}$ and $\mathrm{Mg}$ is similar but more straightforward. According to previous study, ${ }^{25} \mathrm{~d}$-SiO is composed 

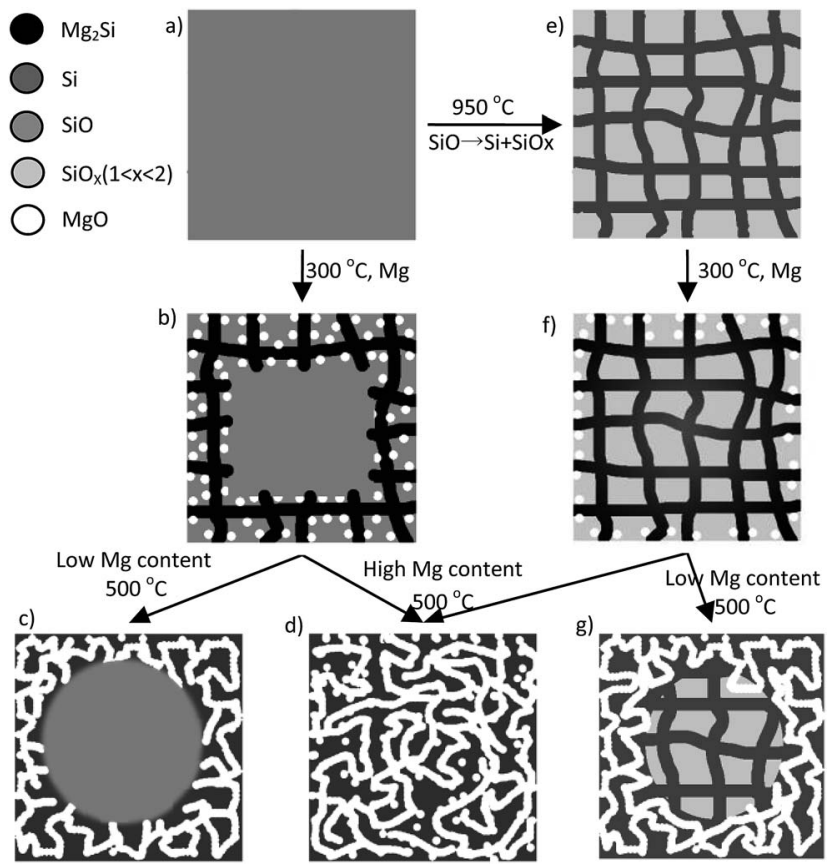

Fig. 5 Schematic illustration of the structural evolution of SiO during magnesiothermic reduction.

of two networks interpenetrated with each other. Although the silicon network in d-SiO could not be clearly observed in Fig. S6, $\dagger$ the silicon network probably formed by connecting silicon grains with amorphous silicon that was invisible in TEM image. Furthermore, the existences of the silicon network could be indirectly proved by the formation of PSi after selectively removing of $\mathrm{SiO}_{x}(1<x<2)$ network. ${ }^{25}$ With this knowledge, we deduced that the preformed silicon network (Fig. 5e) of d-SiO first reacted with $\mathrm{Mg}$ to form $\mathrm{Mg}_{2} \mathrm{Si}$ at $300{ }^{\circ} \mathrm{C}$ (Fig. $5 \mathrm{f}$ ). Meanwhile, some $\mathrm{MgO}$ was formed from the reaction between $\mathrm{Mg}$ and $\mathrm{SiO}_{x}(1<x<2) . \mathrm{Mg}_{2} \mathrm{Si}$ reacted with adjacent $\mathrm{SiO}_{x}(1<x<2)$ to form silicon and $\mathrm{MgO}$ at higher temperatures (Fig. $5 \mathrm{~d}$ and g). The inductive effect of the preformed silicon network was exhibited in the following two roles. First, it acted as a channel for Mg diffusion. Second, it served as a skeleton on which the reduced silicon grows. The inductive effect led to higher BET surface area and pore volume of PSi-06D and PSi-12D as compared with PSi-06 and PSi-12.

\section{Conclusions}

In summary, two types of PSi have been synthesized by the magnesiothermic reduction of SiO and d-SiO. The pore formation mechanisms were thoroughly analysed by comparing the pore structure of PSi reduced by different $\mathrm{Mg}$ contents. Conversion of the $\mathrm{SiO}$ and d-SiO particles into $\mathrm{PSi}$ and $\mathrm{MgO}$ from outside to inside as the $\mathrm{Mg}$ content increased from $0.6 \mathrm{~g}$ of $\mathrm{Mg}$ to $1.8 \mathrm{~g}$ of $\mathrm{Mg}$ per $4.4 \mathrm{~g}$ of SiO was confirmed. The BET surface area and pore volume of these PSi samples increased in turn when the magnesium content increased from 0.60 to $1.80 \mathrm{~g}$ and decreased when the magnesium content increased from 1.80 to $2.40 \mathrm{~g}$ per $4.40 \mathrm{~g}$ of SiO. The highest BET surface area was 304 and $328 \mathrm{~m}^{2}$ $\mathrm{g}^{-1}$ for the PSi obtained from SiO and d-SiO, respectively. These BET surface areas are among the highest of those obtained for PSi prepared from dense SiO and silica. The preformed silicon network in d-SiO exerted an inductive effect on the formation of PSi at low Mg content, which led to a BET surface area and pore volume that were approximately twice as large as those of the PSi from SiO. Accordingly, two models were suggested to describe the formation mechanisms of the PSi derived from SiO and d-SiO. These results are of great importance for precisely controlling the pore structure of PSi prepared from dense SiO or silica.

\section{Acknowledgements}

This work was financially supported by the National Natural Science Foundation of China (No. 51202150 and 51272161), Program of Introducing Innovative Research Team in Dongguan (No. 2014607109), foundation of the State Key Laboratory of Solidification Processing in NWPU (SKLSP201110) and Shenzhen Basic Research Program (No. JCYJ20160422091418366).

\section{Notes and references}

1 A. Xing, J. Zhang, Z. Bao, Y. Mei, A. S. Gordin and K. H. Sandhage, Chem. Commun., 2013, 49, 6743-6745.

2 H.-C. Tao, L.-Z. Fan and X. Qu, Electrochim. Acta, 2012, 71, 194-200.

3 L. Shi, W. Wang, A. Wang, K. Yuan and Y. Yang, J. Alloys Compd., 2016, 661, 27-37.

4 J. Cho, J. Mater. Chem., 2010, 20, 4009-4014.

5 P. Jongho, Y. Yanagida and T. Hatsuzawa, Sens. Actuators, $B$, 2016, 233, 136-143.

6 N. Shrestha, F. Araujo, M. A. Shahbazi, E. Makila, M. J. Gomes, B. Herranz-Blanco, R. Lindgren, S. Granroth, E. Kukk, J. Salonen, J. Hirvonen, B. Sarmento and H. A. Santos, Adv. Funct. Mater., 2016, 26, 3405-3416.

7 T. Yong, J. Hu, X. Zhang, F. Li, H. Yang, L. Gan and X. Yang, ACS Appl. Mater. Interfaces, 2016, 8(41), 27611-27621.

8 B. M. Bang, J.-I. Lee, H. Kim, J. Cho and S. Park, Adv. Energy Mater., 2012, 2, 878-883.

9 B. M. Bang, H. Kim, H.-K. Song, J. Cho and S. Park, Energy Environ. Sci., 2011, 4, 5013-5019.

10 Z. Zhang, Y. Wang, W. Ren, Q. Tan, Y. Chen, H. Li, Z. Zhong and F. Su, Angew. Chem., 2014, 126, 5265-5269.

11 M. Ge, Y. Lu, P. Ercius, J. Rong, X. Fang, M. Mecklenburg and C. Zhou, Nano Lett., 2014, 14, 261-268.

12 P. Wu, H. Wang, Y. Tang, Y. Zhou and T. Lu, ACS Appl. Mater. Interfaces, 2014, 6, 3546-3552.

13 D. Chen, X. Mei, G. Ji, M. Lu, J. Xie, J. Lu and J. Y. Lee, Angew. Chem., Int. Ed., 2012, 51, 2409-2413.

14 K. Chen, Z. Bao, J. Shen, G. Wu, B. Zhou and K. H. Sandhage, J. Mater. Chem., 2012, 22, 16196-16200.

15 Z. Bao, M. R. Weatherspoon, S. Shian, Y. Cai, P. D. Graham, S. M. Allan, G. Ahmad, M. B. Dickerson, B. C. Church, Z. Kang, H. W. Abernathy Iii, C. J. Summers, M. Liu and K. H. Sandhage, Nature, 2007, 446, 172-175.

16 A. Xing, S. Tian, H. Tang, D. Losic and Z. Bao, RSC Adv., 2013, 3, 10145-10149. 
17 Z. Favors, W. Wang, H. H. Bay, Z. Mutlu, K. Ahmed, C. Liu, M. Ozkan and C. S. Ozkan, Sci. Rep., 2014, 4, 5623.

18 H. Jia, P. Gao, J. Yang, J. Wang, Y. Nuli and Z. Yang, Adv. Energy Mater., 2011, 6, 1036-1039.

19 Y. Zhang and J. Huang, J. Mater. Chem., 2011, 21, 7161-7165.

20 Z.-L. Xu, B. Zhang, Z.-Q. Zhou, S. Abouali, M. Akbari Garakani, J. Huang, J.-Q. Huang and J.-K. Kim, RSC Adv., 2014, 4, 22359-22366.

21 L. Wang, B. Gao, C. Peng, X. Peng, J. Fu, P. K. Chu and K. Huo, Nanoscale, 2015, 7, 13840-13847.
22 D. F. Qiu, G. Bu, B. Zhao and Z. X. Lin, J. Solid State Electrochem., 2015, 19, 935-939.

23 W. Wang, Z. Favors, R. Ionescu, R. Ye, H. H. Bay, M. Ozkan and C. S. Ozkan, Sci. Rep., 2015, 5, 8781.

24 S. M. Schnurre, J. Gröbner and R. Schmid-Fetzer, J. NonCryst. Solids, 2004, 336, 1-25.

25 R. Yi, F. Dai, M. L. Gordin, S. Chen and D. Wang, Adv. Energy Mater., 2013, 3, 295-300.

26 I. Kogut and M. C. Record, Thin Solid Films, 2012, 522, 149158. 